\title{
Forensic Importance of Piriform Aperture: An Overview
}

\author{
Manjushri M. Waingade, Pooja Rathod, Madhura Mahajan, Namrata Khandare \\ Department of Oral Medicine and Radiology, Sinhgad Dental College and Hospital, Pune, Maharashtra, India
}

Email for correspondence: manju.waingade@gmail.com

\begin{abstract}
The pelvis and the skull bone are the best expressions of differences attributable to sex. In the skull, the shape of the piriform aperture (PA) is one of the classic indicators of morphological sexual dimorphism. PA shows racial and geographical differences due to variable climate. Racial differences in the shape and size of the nasal bones and PA have been reported, and these must be taken into account in neurosurgery, rhinology, and otolaryngology, and plastic and reconstructive facial surgery. It would help surgeons in surgical modifications of this area for the best suitable air passage modifications according to morphological and functional variations. Knowledge of these morphological variations can serve as a useful data set to delineate the anthropological characteristics of the population. As the skeletal structure of human face is influenced by environmental factors, specific standards of assessment must be drawn and applied to particular population under consideration. Thus, the present review gives a brief outline of the studies reported in literature that may be useful for anthropologist, forensic researchers, otorhinologist, and plastic surgeons.
\end{abstract}

Key words: Anthropology, ethnic, forensic, piriform aperture, racial, sexual dimorphism

\section{INTRODUCTION}

The process by which we recognize males and females within a population is based on the quick and systematic assessment of all dimorphic features, more highly accurate methods for diagnosis according to sex. ${ }^{[1]}$ The shape of the piriform aperture (PA) is one of the classic indicators of morphological sexual dimorphism. ${ }^{[2]}$ The PA is an anatomical structure that usually has a pear-shaped appearance, anatomically formed in its upper portion by the nasal bone, palatal process of the maxilla inferiorly and laterally by the frontal process of the maxilla. There is a racial and geographical difference in the shape of the nose and the nasal aperture due to climatic variation. ${ }^{[3,4]}$ Their form and size may also serve as a basis for anthropological studies of

\begin{tabular}{|c|c|}
\hline Quick Response Cod & Article Info: \\
\hline & doi: 10.5866/2019.11.10108 \\
\hline & $\begin{array}{l}\text { Received: } 18-07-2019 \\
\text { Revised: } 19-08-2019 \\
\text { Accepted: } 27-08-2019 \\
\text { Available Online: 01-10-2019, (www. } \\
\text { nacd.in) @ NAD, } 2019 \text { - All rights reserved }\end{array}$ \\
\hline
\end{tabular}

a specific population, related to ethnicity. ${ }^{[3,5]}$ This variation is necessary to adapt to the physiological and functional needs of climate. ${ }^{[1,3]}$ These changes occur with respect to external nasal morphology, orientation of nasal bone, and PA and in the mucosa lining, the internal passages. ${ }^{[4,6]}$ The knowledge of the morphometric measurements of nasal bone and PA is of relevance for performing a surgical procedure such as rhinoplasty, osteotomies, and plastic reconstructions. Studies have shown that surgical and traumatic alterations of the PA may alter the respiratory mechanics. ${ }^{[3,4,6]}$ The PA and nasal bones morphology vary according to ethnic groups. This morphological variability is necessary to understand the geographic and ethnic differences and can be analyzed by radiography in forensic context. ${ }^{[2,5,7]}$ In addition to forensic implications, the knowledge of the PA and nasal bone variations is fundamentally significant in anthropology and otolaryngology. ${ }^{[2]}$ The present review gives a brief outline of the forensic value of PA.

\section{ANATOMY OF PA}

The PA is the large opening in the nasal region and the anterior opening of the nasal cavity. The 
nasal cavity extends from the external nares or nostrils to the posterior nasal apertures and is subdivided into the right and left halves by the nasal septum [Figure 1]. Each half has a roof, a floor, and medial and lateral walls. The two nasal bones articulate at midline to form internasal suture. Superiorly, both nasal bones articulate with frontal bone and form frontonasal suture. Intersection of frontonasal and internasal suture is called nasion. Thin inferior border is attached to the lateral cartilage of the nose and contributes to anterior nasal opening called PA. The lateral border articulates to the frontal process of the maxilla. ${ }^{[3,7-9]}$ Inferiorly, the PA is the large opening in the nasal region and the anterior opening of the nasal cavity. It is bounded superiorly by the nasal bones and laterally and inferiorly by each maxilla. Visible through the PA is the fused nasal crests, forming the lower part of the bony nasal septum and ending anteriorly as the anterior nasal spine, and the paired inferior nasal conchae. ${ }^{[8]}$

\section{EMBRYOLOGY OF THE PA}

The development of piriform aperture is thought to be complete by the $8^{\text {th }}$ week of gestation. Warbrick described four stages of embryologic development of the nose. The first stage is the formation of the nasal placodes. During the second stage, the nasal groves arise from the nasal placodes. In the third stage, the nasal groves transform into the nasal pits and at the fourth stage see the deepening of the nasal pits and the formation of the primitive posterior nares. The anterior nares are formed from fusion of the maxillary process with the lateral and medial nasal process. From the $8^{\text {th }}$ to the $24^{\text {th }}$ week of gestation, the nostril is filled by an epithelial plug. It is the failure of this plug to reabsorb which results in stenosis of the anterior nares. ${ }^{[10,11]}$

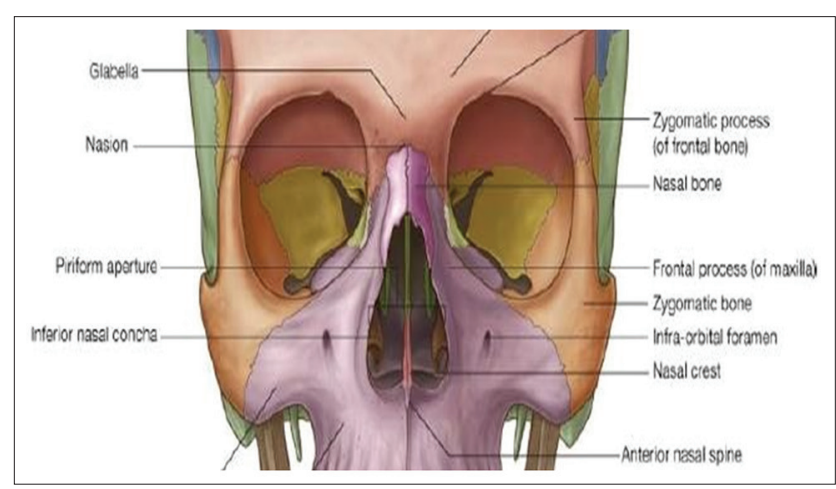

Figure 1: Anatomy of piriform aperture

\section{FORENSIC EVALUATION OF PA}

Rogers and Williams and Rogers found that the shape of the PA was a good indicator for the diagnosis of sex. In addition, morphometric studies in PA in German and Korean populations showed the presence of sexual dimorphism in some of its dimensions. ${ }^{[12-16]}$ Various authors have conducted anthropological studies done to assess PA measured on dry skulls, 2D radiographs, computed tomography (CT) scans, and cone-beam CT for forensic evaluation [Table 1].

The following conclusions can be drawn:

1. Width of PA in Anatolian people is smallest compared to all populations

2. Brazilians have PA height well above all the populations.

\section{RACIAL AND GENDER DIFFERENCES IN PA}

Various eco-geographical variations in the nasal passage have been described. Caucasians have greater nasal cavity height and lengths and smaller breadths than African-Americans. In the decongested nose, the Caucasian nose shows a much higher surface area-to-volume-ratio than the decongested African-American nose. ${ }^{[9]}$ Looking at differences between Caucasians, Chinese, and Indians, Abdelkader et al. showed no significant difference in the lengths and width of the columella, but the PA was longer in the Indian group, and the maximum with of the aperture was narrowest in the Chinese group. Afro-Americans have been found to have a more oval-shaped PA, resulting in larger piriform openings. ${ }^{[5]}$ According to Ofodile, the shape of the PA was oval in Ashanti, triangular in Austrians and American Indians, and varied from oval to triangular in African Americans. ${ }^{[3,5]}$ Ofodile suggested that Anatolian widths of PAs were the narrowest while the Ashanti were the widest. The width of PAs of Iranian people was narrower than the Ashanti and American Indians' and somewhat equal to the Koreans' and Germans' and was wider than the African Americans, Austrians', and Anatolians'. The Ashanti nasal bones were the shortest. These data were consistent with the climate influence. The height of Iranians' nasal bones in this study was shown to be shorter than Anatolians', Austrians', American Indians', and African Americans and somewhat equal to the Koreans' and Germans' and longer than the Ashanti. ${ }^{[3,4]}$

The lower width of the PA in Koreans was longer than that in Caucasians and shorter than that in 


\begin{tabular}{|c|c|c|c|c|c|c|c|c|}
\hline \multirow[t]{2}{*}{ Study/year } & \multirow[t]{2}{*}{ Population } & \multirow[t]{2}{*}{ Techniques } & \multicolumn{2}{|c|}{$\begin{array}{l}\text { PA height } \\
\quad(\mathbf{m m})\end{array}$} & \multicolumn{2}{|c|}{$\begin{array}{l}\text { PA width } \\
\text { (mm) }\end{array}$} & \multirow[t]{2}{*}{$\begin{array}{l}\text { Mean width } \\
\quad(\mathrm{mm})\end{array}$} & \multirow{2}{*}{$\begin{array}{c}\begin{array}{c}\text { Importance in } \\
\text { sexual dimorphism }\end{array} \\
\text { Yes/No/ND }\end{array}$} \\
\hline & & & $\mathbf{M}$ & $\mathbf{F}$ & M & $\mathbf{F}$ & & \\
\hline Lang et al..$^{[17]}$ & German & PA Caldwell & - & - & - & - & 23.6 & ND \\
\hline $\begin{array}{l}\text { Hommerich and } \\
{\text { Riege }{ }^{[14]}}\end{array}$ & German & 116 dry skulls & - & - & 23.6 & 22.6 & 23.1 & Yes \\
\hline Hoffman et al..$^{[18]}$ & $\begin{array}{l}\text { American } \\
\text { Whites }\end{array}$ & - & - & - & - & - & 23.7 & ND \\
\hline Yüzba io lu et al. ${ }^{[19]}$ & Turkish & Skull CT & 33.4 & 30.1 & 24.6 & 23.3 & 23.95 & Yes \\
\hline Hwang et al. ${ }^{[15]}$ & Korean & Dry skull & 30.1 & 28 & 25.7 & 25.4 & 25.5 & Yes \\
\hline $\begin{array}{l}\text { Zamani Naser and } \\
\text { Panahi Boroujeni }{ }^{4]}\end{array}$ & Turkish & MDCT & - & - & 25.67 & 23.77 & 24.72 & No \\
\hline Moreddu et al. ${ }^{[20]}$ & France & 3D-CT & 32.54 & 36.35 & 25.32 & 24 & 24.66 & Yes \\
\hline Karadag et al. ${ }^{[7]}$ & Anatolian & $\mathrm{CT}$ & - & - & 18.83 & 18.19 & 18.51 & ND \\
\hline Ofodile $^{[5]}$ & Austrian & Dried skull & - & - & - & - & 21.6 & ND \\
\hline Lee et al..$^{[16]}$ & Korean & 3D-CT & - & - & 24.34 & 22.82 & 23.58 & Yes \\
\hline Prado et al. ${ }^{[2]}$ & Brazilian & X-ray & - & - & 17.60 & 17.20 & 17.4 & Yes \\
\hline Asghar et al. ${ }^{[3]}$ & North Indian & Dry skull & 31.16 & 29.57 & 24.9 & 22.77 & 24.15 & Yes \\
\hline Cantin et al. ${ }^{[1]}$ & Brazilian & Dry skull & 50.82 & 47.53 & 26.87 & 25.26 & - & Yes \\
\hline Erdem et al. ${ }^{[21]}$ & Turkish & Dry skull & - & - & 21.9 & 21 & - & Yes \\
\hline
\end{tabular}

PA: Piriform aperture, CT: Computed tomography, MDCT: Multidetector computed tomography, 3DCT: Three-dimensional computed tomography

African Americans. ${ }^{[14,15,17,18]} \mathrm{PA}$ in the Ashanti was oval, while in Austrians and American Indian, the aperture was a triangular shape. In African Americans, the PA varied from triangular to oval, showing differences in different population groups. [1]

Anthropological studies suggest that climatic influence affects the width or breadth and height of the PA. ${ }^{[19-23]}$ The PA directly affects the heating and humidity of the inspired air. In cold and dry climates, the heating and humidification of inhaled air is facilitated by a longer nasal passage and a narrower PA due to increased surface and longer period during which the air is inspired. For this reason, it is speculated that the shape of the $\mathrm{PA}$ is adapted to the environment in a way that reflects geographical variations. ${ }^{[5,15,16]}$ However, sometimes, a close PA can be found as a congenital anatomic variation. ${ }^{[14]}$

The characteristics of the PA have been regarded as a classic indicator of sexual dimorphism. Differences in the width and height of the PA show higher values among males. Differences in the height of the PA were more significant among individuals who are Caucasians, African Americans, and Latinos. In the skulls of Black individuals, significant differences were observed in the upper width of the PA. ${ }^{[1]}$ Prescher et al. assessed 184 human skulls and described the PA in males to have a higher and larger area. In females, the PA is relatively wide in caudal, but becomes reduced cranially. The PA in both cases had a pear shape, where the two seem quite similar but not identical. ${ }^{[24]}$

\section{CONCLUSION}

The present review provides a brief outline of the studies reported about the forensic importance of PA. Thus, PA is a very good indicator of sexual dimorphism and ethnic background and holds a promising landmark in forensic assessment.

\section{REFERENCES}

1. Cantin LM, Claudio SG, Alejandra ZM, Smith RL. Sexual dimorphism determination by Piriform aperture morphometric analysis in Brazilian human skulls. Int $J$ Morphol 2009;27:327-31.

2. Prado FB, Caldas RA, Rossi AC, Freire AR, Groppo FC, Caria $\mathrm{PH}$, et al. Piriform aperture morphometry and nasal bones morphology in Brazilian population by posteroanterior Caldwell radiography. Int J Morphol 2011;29:393-8.

3. Asghar A, Dixit A, Rani M. Morphometric study of nasal bone and Piriform aperture in human dry skull of Indian origin. J Clin Diagn Res 2016;10:AC05-7.

4. Zamani Naser A, Panahi Boroujeni M. CBCT evaluation of 
bony nasal pyramid dimensions in Iranian population: A comparative study with ethnic groups. Int Sch Res Notices 2014;2014:819378

5. Ofodile FA. Nasal bones and pyriform apertures in blacks. Ann Plast Surg 1994;32:21-6.

6. Devi GD, Archana R, Johnson WM. Morphometric study of nasal bone and Piriform aperture in human dry skull of south Indian origin. Int J Anat Res 2018;6:5970-3.

7. Karadag D, Ozdol NC, Beriat K, Akinci T. CT evaluation of the bony nasal pyramid dimensions in Anatolian people. Dentomaxillofac Radiol 2011;40:160-4.

8. Gray H, Standring S, Ellis H, Berkovitz BK. Gray's Anatomy: The Anatomical Basis of Clinical Practice. $39^{\text {th }}$ ed. Edinburgh: Elsevier Churchill Livingstone; 2005.

9. Yokley TR. Ecogeographic variation in human nasal passages. Am J Phys Anthropol 2009;138:11-22.

10. Kumoi T, Nishimura Y, Shiota K. The embryologic development of the human anterior nasal aperture. Acta Otolaryngol 1993;113:93-7.

11. Papesh E. The nasal Piriform aperture and its importance. Otorhinolaryngol Head Neck Surg 2016;1:89-91.

12. Rogers TL. Determining the sex of human remains through cranial morphology. J Forensic Sci 2005;50:493-500.

13. Williams BA, Rogers T. Evaluating the accuracy and precision of cranial morphological traits for sex determination. J Forensic Sci 2006;51:729-35.

14. Hommerich CP, Riegel A. Measuring of the Piriform aperture in humans with 3D-SSD-CT-reconstructions. Ann Anat 2002;184:455-9.

15. Hwang TS, Song J, Yoon H, Cho BP, Kang HS. Morphometry of the nasal bones and Piriform apertures in Koreans. Ann Anat 2005; $187: 411-4$

16. Lee SH, Yang TY, Han GS, Kim YH, Jang TY. Analysis of the nasal bone and nasal pyramid by three-dimensional computed tomography. Eur Arch Otorhinolaryngol 2008;265:421-4

17. Lang J, Baumeister R. Uberdas post natale wachstum der nasenhöhle. Gegenbaurs Morphol Jahrb 1982;128:354-9393.

18. Hoffman BE, McConathy DA, Coward M, Saddler L. Relationship between the Piriform aperture and interalar nasal widths in adult males. J Forensic Sci 1991;36:1152-61.

19. Yüzbaşioğlu N, Yilmaz MT, Çicekcibasi AE, Şeker M, Sakarya ME. The evaluation of morphometry of nasal bone and pyriform aperture using multidetector computed tomography. J Craniofac Surg 2014;25:2214-9.

20. Moreddu E, Puymerail L, Michel J, Achache M, Dessi P, Adalian P. Morphometric measurements and sexual dimorphism of the Piriform aperture in adults. Surg Radiol Anat 2013;35:917-24

21. Erdem T, Ozturan O, Erdem G, Akarcay M, Miman MC Nasal pyriform aperture stenosis in adults. Am J Rhinol 2004;18:57-62.

22. Abdelkader M, Leong S, White PS. Aesthetic proportions of the nasal aperture in 3 different racial groups of men. Arch Facial Plast Surg 2005;7:111-3

23. Wolpoff MH. Climatic influence on the skeletal nasal aperture. Am J Phys Anthropol 1968;29:405-23.

24. Prescher A, Meyers A, Gerf von Keyserlingk D. Neural net applied to anthropological material: A methodical study on the human nasal skeleton. Ann Anat 2005;187:261-9. 